\title{
Evaluation of the prevalence of folic acid supplementation before conception and through the first 12 weeks of pregnancy in Polish women at high risk of fetal anomalies
}

\author{
Anna Wojtowicz $\mathbb{D}^{\circ}$, Dorota Babczyk, Aleksander Galas ${ }^{\circledR}$, Malgorzata Skalska-Swistek, \\ Magdalena Gorecka, Rafal Witkowski, Hubert Huras ${ }^{(1)}$ \\ Collegium Medicum, Jagiellonian University, Cracow, Poland
}

\begin{abstract}
Objectives: Local and international organizations recommend folic acid (FA) supplementation in the periconceptional period. This study aimed to analyse the prevalence of periconceptional supplementation with FA in women at high risk of fetal anomalies refferred for first trimester screening.

Material and methods: Our analysis involved 1,455 women at high risk of fetal anomalies refferred for first trimester screening. FA supplementation was assessed by face-to-face interviews conducted by doctors performing first trimester screening for aneuploidy.

Results: FA supplementation before pregnancy was reported by $46.8 \%$ of the women and during the first trimester by $57.2 \%$ of those studied. Women used FA supplementation more frequently if they had a history of at least one miscarriage (OR 2.2, 95\% Cl 1.70-2.83; $\mathrm{p}<0.001$ ), a history of assissted reproductive techniques (OR 2.25, 95\% Cl 1.18-4.31; $\mathrm{p}=0.014$ ), or were aged between 30 and 34 (OR 2.87, 95\% Cl 1.47-5.58; $p=0.002$ ). Among 122 women with a history of fetal defects only $50 \%$ confirmed FA supplementation before pregnancy and $62.2 \%$ during pregnancy $(p=0.488)$. A similar frequency of FA supplementation was noted among women with epilepsy, diabetes, and hypertension. Less frequent taking of FA was noted among women at least third and subsequent pregnancies $(p<0.001)$. In the current pregnancy, neural tube defects (NTDs) were less frequent by $86 \%$ in the group of women with FA supplementation than in the non-supplementation group ( 1 case vs 6 cases, respectively) and for other fetal defects by $62.5 \%$ (24 vs 40 cases, respectively).

Conclusions: We found an unsatisfactory compliance with recommendations for the use of folic acid supplementation during periconceptional period among women at high risk of fetal defects and folate deficiency, that could have negative effects on the health of child and mother. The study results show the need to increase the awareness of FA supplementation during periconceptional period especially in women with high risk of fetal anomalies.
\end{abstract}

Key words: folic acid supplementation; pregnancy; fetal defects; epidemiology

Ginekologia Polska 2022; 93, 6: 489-495

\section{INTRODUCTION}

During pregnancy, the need for basic nutrients, vitamins and minerals increases due to the development of the fetus, placenta and maternal tissues [1, 2]. One of the most important elements necessary for the synthesis of nucleic acids in rapidly dividing cells is folate. Folate is also essential in protein synthesis processes, reducing reactive oxygen species, epigenetic regulation, enzymatic processes, transcription pathways, and signal transduction [2-4]. It has been shown that folic acid (FA) alone, or in combination with other minerals and vitamins taken during periconception (the time preceding the woman's conception until the $12^{\text {th }}$ week of gestation) prevents neural tube defects (NTDs) such as anencephaly, spina bifida or encephalocele

\footnotetext{
Corresponding author: 
in fetus [5-9]. Studies also indicate that folate deficiency may be associated with a higher risk of defects of the heart, urinary tract, limbs, cleft palate as well as being associated with a higher risk of preeclampsia [8-11]. The World Health Organization (WHO) $[3,4,12]$ and most European countries [13] recommend that all women, during periconception, should take $400 \mu \mathrm{g}$ of folic acid daily as a supplement. In Poland, in accordance with the 2017 [14] and 2020 [15] recommendations of the Polish Society of Gynecologists and Obstetricians, all women of reproductive age should take FA as a supplement to a natural, folate-rich diet and such supplementation should be continued through pregnancy and lactation. Moreover, the Polish reccomendations state that doses should depend on the woman's history of NTDs or other fetal defects in prior pregnancies and/or their risk of folate deficiency $[14,15]$. Therefore, for those women with a low-risk of fetal defects and pregnancy complications, a dose of $400 \mu \mathrm{g} /$ day is sufficient; compared with those in an increased-risk or high-risk group. In the increased-risk group, which includes women with fetal defects in their own or close family history, a history of IUGR/preeclampsia, pregestational diabetes, digestive diseases, hepatic failure, renal failure, bariatic surgery, obesity, smoking, using anti-epileptic drugs, metformin, methotrexate, cholestyramine, sulfasalazine or with reduced MTHFR activity, folate at a dose of $0.8 \mathrm{mg} /$ day including active folate and vitamin B12 within 12 weeks before planned pregnancy, during pregnancy and lactation is advised.

In turn, in the high-risk group with a history of NTDs in the mother, father or their offspring, $5 \mathrm{mg} /$ day including active folate and vitamin B12 within 12 weeks before planned pregnancy and in the first trimester of pregnancy, and subsequently, $0.8 \mathrm{mg} /$ day during the second and third trimesters and the period of lactation are recommended $[14,15]$.

It is estimated that $70-98 \%$ of pregnant women in countries in Europe and the USA use dietary supplements $[1,2]$. In Europe, where it is reported that as many as $45 \%$ of pregnancies may be unintended [16], FA supplementation is significantly lower; for instance, a recently published paper by Camier et al. [17] showed that only $26 \%$ of French women received folic acid supplementation during their periconceptional period. Hence, the aim of this study was to analyze the prevalence of supplementation with FA during the periconceptional period in women at high risk of fetal anomalies refferred for first trimester screening.

\section{MATERIAL AND METHODS}

We carried out a retrospective cohort study at one tertiary centre for the prenatal diagnosis and management of fetal and neonatal pathology (the Department of Obstetrics and Perinatology in (racow, Poland). The study is a ret-

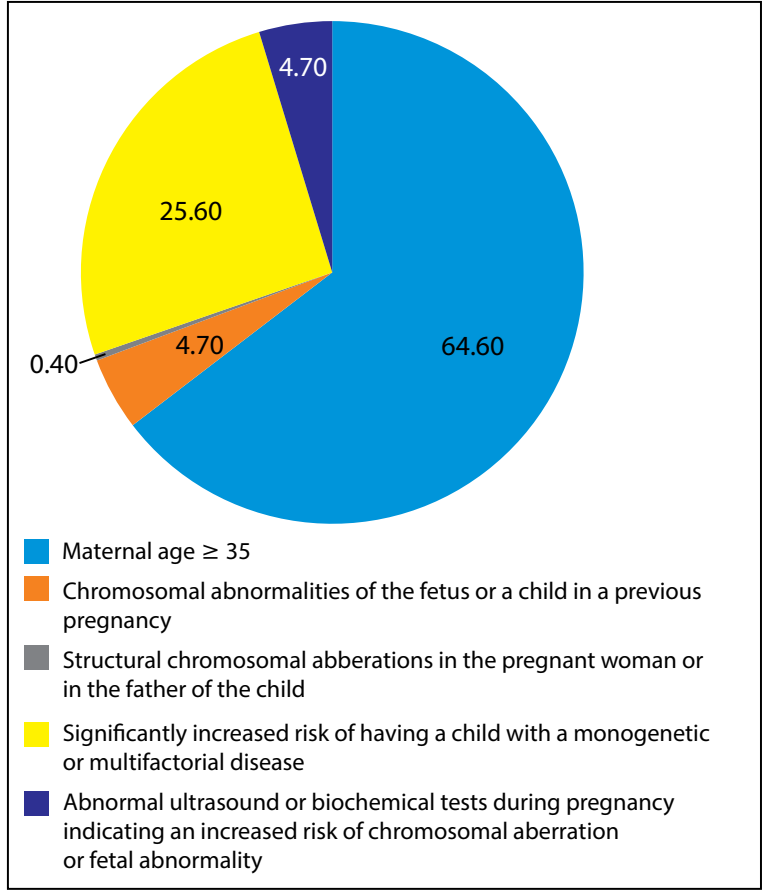

Figure 1. Distribution of indications expressed in percentages for pregnant women referred for first trimester screening for aneuploidy [18]

rospective analysis of the medical records of 1,455 pregnant women referred for first trimester screening for fetal aneuploidy, who met criteria esthablished by the Polish National Health Fund (Fig. 1) [18]. Multiple pregnancies were excluded from the analysis. We also excluded patients whose records were incomplete and did not contain data on supplementation and the use of other drugs as well as patients under 18 years of age, with cancer, organ transplant or intellectual disabilities. Women were interviewed between January 2017 and December 2019 regarding their indications for the examination, accompanying diseases, use of supplements with FA before pregnancy and during the first 12 weeks of pregnancy. The interviews also collected information about the women's previous pregnancies, and family history of NTDs or any other structural or genetic anomalies.

Data were collected through standardized face-to-face interviews conducted by trained physiscians and prior to the woman's ultrasound scan. Each woman was asked the following questions: 1. Have you taken FA before pregnancy? 2. Have you taken FA during pregnancy? 3. Have you taken multivitamin supplements during pregnancy? Have you taken any medications and if so, which ones?

In addition, we analysed the results of first trimester screening for aneuploidy. First trimester screening was performed following Fetal Medicine Foundation, UK, and Polish national guidelines $[19,20]$. Nuchal translucency 
(NT) above the $95^{\text {th }}$ percentile was considered abnormal. Ultrasound examinations were carried out using a Voluson E6 (GE Healthcare Medical Systems, Milwaukee, WI, USA).

The institutional review board waived the requirement for a separate ethical approval for this analysis, since the interview and sonographic evaluations were both performed as integral parts of routine clinical care, for which informed consent had been previously given by the women. Data were anonymized.

\section{Statistical analysis}

Patient characteristics are described as means with standard deviation for normally distributed numerical data and as percentages for categorical variables. Differences were analyzed by the Student's t-test for normally distributed data and the Mann-Whitney U-test for non-normally distributed data. Chi-square and Fisher's exact tests were used for comparisons of categorical variables determined by whether the assumption of the expected values more than five was fullfilled or not. As a first step of analysis a comparison of selected maternal risk factors in groups of declared folic acid supplementation before pregnancy has been done. Next only those variables, which were identified as significant were put into multivariable binomial logistic regression. The model enabled to assess the association between identified factors and the presence of folic acid supplementation before pregnancy. The strength of the association has been measured by the odds ratios (ORs), and the multivariable logistic regression model provided information after the adjustement for all the others coviariates presented in the model. Additionally, to show the precision level for OR estimates, 95\% confidence intervalls (Cls) were provided. In all analyses, $\mathrm{p}$ values $<0.05$ were considered statistically significant.

\section{RESULTS}

Selected maternal risk factors for adverse pregnancy outcomes in the study cohort are listed in Table 1 and 2. Most of women (66\%) had a normal body mass index (BMI). A quarter of women had a history of at least one miscarriage. For $73.7 \%$ of the women, it was their first or second pregnancy. The most common comorbidity was hypothyroidism which affected $18 \%$ of cases. FA supplementation before pregnancy was declared by $46.8 \%$ of the women, and that during first trimester by $57.2 \% .88 .2 \%$ of patients declared FA dose of $400 \mu \mathrm{g}$ before pregnancy and $11.8 \%$ declared dose was 800 ug of activate folate or more. During first trimester 226 women (33.2\%) have taken FA in multivitamin kits containing $800 \mu \mathrm{g}$ of activate folate. In turn, in group of women who did not supplement FA before pregnancy, 157 (20.2\%) started using multivitamin supplements during pregnancy. The main $(64.7 \%)$ reason for screening was maternal age of 35 years or more, and of these women, $42.5 \%$ reported using FA supplementation before pregnancy. However, the highest incidence (59.4\%) of supplementation was observed among women with a history of fetal chromosomal abnormalities or having a child by a previous pregnancy (Tab. 2). Considering the risk of fetal defects and pregnancy complications, $60 \%$ of the women were in the intermediate-risk group, and only $2 \%$ in the high-risk group; and it was in that latter group that FA supplementation was the most frequent (62\%) (Tab. 2). Women reporting FA supplementation were more likely to have had a history of at least one miscarriage (OR 2.2, 95\% Cl 1.70-2.83; $\mathrm{p}<0.001)$, a history of assissted reproductive techniques (ART) (OR 2.25, 95\% $\mathrm{Cl} 1.18-4.31 ; p=0.014)$, or were aged between 30 and 34 (OR 2.87, 95Cl 1.47-5.58; $\mathrm{p}=0.002$ ) (Tab.3). Fewer instances of FA supplementation were noted among women in their $\geq 3^{\text {rd }}$ pregnancy $(p<0.001$ ) (Tab. 3). Among the 122 women with a history of fetal defects, only $50 \%$ confirmed their use of FA supplementation before pregnancy, and $62.2 \%$ during pregnancy (OR 1.16, 95\% Cl 0.76-1.76; $\mathrm{p}=0.488$ ). A similar frequency of FA supplementation before pregnancy was noted among women with epilepsy (50\%), diabetes (56.5\%), or hypertension (53.2\%); and, similarly, for those during their first trimester (54.5\%; 65.7\%; or 59.6\%, respectively) (Tab. 1).

Of the group of women with FA supplementation, 24 (3.5\%) cases of fetal defects were detected during the first trimester screening; and in the group without FA supplementation $40(5.1 \%)$ cases were found (Tab. 4), thus fetal defects were found $62.5 \%$ less frequent in those with FA supplementation. Among women who declared FA supplementation before pregnancy, a history of NTDs in previuos pregnancies was observed in $1.2 \%$ instances and in $1.1 \%$ of those women who did not supplement FA. In the current pregnancy, neural tube defects (NTDs) were less frequent by $86 \%$ in the group of women with FA supplementation than in the non-supplementation group ( 1 case vs. 6 cases, respectively) (Tab. 4).

\section{DISCUSSION}

To our knowledge this is the first study concerning FA supplementation before pregnancy and during the first trimester in a large cohort of Polish pregnant women with high risk of fetal anomalies reffered for first trimester screening. Our study showed a generally unsatisfactory frequency of FA supplementation during the periconceptional period, indicating the need for education in this field.

Studies carried out in recent years indicate that a 12-week precontraceptive period of supplementation is necessary to obtain the appropriate concentration of folate in blood cells [1, 17]. Bitzer et al. [22] showed that less than $40 \%$ of European women of child-bearing age had ever taken FA. In that study only $28 \%$ of women trying to conceive had taken FA compared with $55 \%$ of women during their 
Table 1. The distribution of selected maternal risk factors for adverse pregnancy outcomes in 1,455 women with singleton pregnancy during first trimester screening for aneuploidy

\begin{tabular}{|c|c|c|c|c|}
\hline & Total & Folic acid suppleme & d before pregnancy & p-value \\
\hline & {$[n=1455]$} & Yes $[n=681]$ & No $[n=774]$ & \\
\hline Maternal age < $35, \mathrm{n}(\%)$ & $514(35.3)$ & $281(54.7)$ & $233(45.3)$ & $\mathrm{p}^{\mathrm{chi} 2}<0.001$ \\
\hline Maternal age $\geq 35, \mathrm{n}(\%)$ & $941(64.7)$ & $400(42.5)$ & $541(57.5)$ & \\
\hline $\mathrm{BMI}<18.5, \mathrm{n}(\%)$ & $44(3.0)$ & $18(40.9)$ & $26(59.1)$ & $\mathrm{p}^{\mathrm{chi2}}=0.267$ \\
\hline BMI 18.5-24.99, n (\%) & $960(66.0)$ & $458(47.7)$ & $502(52.3)$ & \\
\hline BMI 25-29.9, n (\%) & $321(22.0)$ & $150(46.7)$ & $171(53.3)$ & \\
\hline BMI 30-34.9, n (\%) & $95(6.5)$ & $45(47.4)$ & $50(52.6)$ & \\
\hline BMI 35-39.9, n (\%) & $22(1.5)$ & $5(22.7)$ & $17(77.3)$ & \\
\hline $\mathrm{BMI}>40, \mathrm{n}(\%)$ & $13(1.0)$ & $5(38.5)$ & $8(61.5)$ & \\
\hline Parity: & & & & $\mathrm{p}^{\mathrm{chi} 2}<0.001$ \\
\hline First child, n (\%) & $491(33.7)$ & $273(55.6)$ & $218(44.4)$ & \\
\hline Second child, n (\%) & $582(40.0)$ & $307(52.7)$ & $275(47.3)$ & \\
\hline Third child, n (\%) & $280(19.3)$ & $88(31.4)$ & $192(68.6)$ & \\
\hline Fourth child and more, $\mathrm{n}(\%)$ & $101(7.0)$ & $13(12.7)$ & $89(87.3)$ & \\
\hline History of miscarriage & & & & $\mathrm{p}^{\mathrm{chi2}}<0.001$ \\
\hline Yes, n (\%) & $371(25.5)$ & $230(62.0)$ & $141(38.1)$ & \\
\hline No, $n(\%)$ & $1084(74.5)$ & 451 (41.6) & $633(58.4)$ & \\
\hline Known fetal defects in previous pregnancies $n(\%)$ & {$[n=896]$} & {$[n=384]$} & {$[n=512]$} & $\mathrm{p}^{\mathrm{chi2}}=0.104$ \\
\hline Yes, n (\%) & $123(13.7)$ & $61(49.6)$ & $62(50.4)$ & \\
\hline No, n (\%) & $773(86.3)$ & $323(41.8)$ & $450(58.2)$ & \\
\hline $\begin{array}{l}\text { Smoking status } \\
- \text { Never smoked, } n(\%) \\
\text { - Smoked only before pregnancy, } \mathrm{n}(\%) \\
\text { - Smoked before pregnancy and during first } \\
\text { trimester, } \mathrm{n}(\%)\end{array}$ & $\begin{array}{c}1101(75.7) \\
309(21.2) \\
45(3.1)\end{array}$ & $\begin{array}{c}556(50.5) \\
118(38.3) \\
7(15.2)\end{array}$ & $\begin{array}{c}545(49.5) \\
190(61.7) \\
39(84.8)\end{array}$ & $\mathrm{p}^{\mathrm{chi} 2}<0.001$ \\
\hline Diabetes Mellitus & & & & $\mathrm{p}^{\mathrm{chi2}}=0.078$ \\
\hline Yes, n (\%) & $76(5.2)$ & $43(56.6)$ & $33(43.4)$ & \\
\hline No, $n(\%)$ & $1378(94.8)$ & $637(46.2)$ & $741(53.8)$ & \\
\hline Hypertension & & & & $\mathrm{p}^{\mathrm{chi2}}=0.300$ \\
\hline Yes, n (\%) & $62(4.2)$ & $33(53.2)$ & $29(46.8)$ & \\
\hline No, n (\%) & $1393(95.7)$ & $648(46.5)$ & $745(53.5)$ & \\
\hline Hypothyroidism & & & & $\mathrm{p}^{\text {chi2 }}<0.001$ \\
\hline Yes, n (\%) & $263(18.1)$ & $164(62.4)$ & $99(37.6)$ & \\
\hline No, n (\%) & $1192(81.9)$ & $517(43.4)$ & $675(56.6)$ & \\
\hline Epilepsy & & & & $\mathrm{p}^{\mathrm{chi2}}=0.762$ \\
\hline Yes, n (\%) & $22(1.5)$ & $11(50.0)$ & $11(50.0)$ & \\
\hline No, n (\%) & $1433(98.5)$ & $670(46.8)$ & $763(53.2)$ & \\
\hline Assisted reproductive technology & & & & $\mathrm{p}^{\text {chi2 }}<0.001$ \\
\hline Yes, n (\%) & $54(3.7)$ & $40(74.1)$ & $14(25.9)$ & \\
\hline No, $n(\%)$ & $1401(96.3)$ & $641(45.8)$ & $760(54.2)$ & \\
\hline
\end{tabular}

$\mathrm{BMI}$ - body mass index; $\mathrm{p}^{\text {chi2 }}$ - the $\mathrm{p}$-value from the chi-square test

pregnancy [22]. In the Bitzer study, which used a structured on-line questionnaire, the highest rates of awareness and knowledge of FA and its benefits were among women in Poland and the UK. However, in our Polish study only $46 \%$ of women reported using FA supplementation before their pregnancy compared with $57 \%$ during their first trimester. Thus, during the most important period of organogenesis, only about half of the women used FA supplementation. 
Table 2. Folic acid supplementation by the main indication for first trimester screening [18] and by the risk score of fetal defects and pregnancy complications [21]

\begin{tabular}{|c|c|c|c|c|}
\hline & \multirow{2}{*}{$\begin{array}{c}\text { Total } \\
{[n=1455]}\end{array}$} & \multicolumn{2}{|c|}{ Folic acid supplementation before pregnancy } & \multirow[t]{2}{*}{ p-value } \\
\hline & & Yes $[n=681]$ & No $[n=774]$ & \\
\hline \multicolumn{5}{|c|}{ The main indication for first trimester screening } \\
\hline Maternal age > 35, $\mathrm{n}(\%)$ & $940(64.6)$ & $400(58.7)$ & $540(69.8)$ & $\mathrm{p}^{\mathrm{chi} 2}<0.001$ \\
\hline $\begin{array}{l}\text { Chromosomal abnormalities of the fetus or a child in } \\
\text { a previous pregnancy, } n(\%)\end{array}$ & $69(4.7)$ & $41(6.0)$ & $28(3.6)$ & $\mathrm{p}^{\text {chi2 }}<0.05$ \\
\hline $\begin{array}{l}\text { Structural chromosomal aberrations in the pregnant } \\
\text { woman or in the father of the child, } n(\%)\end{array}$ & $6(0.4)$ & $3(0.4)$ & $3(0.3)$ & $\mathrm{p}^{\mathrm{chi2}}=0.760$ \\
\hline $\begin{array}{l}\text { Significantly increased risk of having a child with } \\
\text { a monogenetic or multifactorial disease, } n(\%)\end{array}$ & $373(25.6)$ & $207(39.6)$ & $166(21.4)$ & $\mathrm{p}^{\text {chi2 }}<0.001$ \\
\hline $\begin{array}{l}\text { Abnormal ultrasound or biochemical tests during } \\
\text { pregnancy indicating an increased risk of chromosomal } \\
\text { aberration or fetal abnormality, } \mathrm{n}(\%)\end{array}$ & $67(4.6)$ & $30(4.4)$ & $37(4.8)$ & $\mathrm{p}^{\mathrm{chi2}}=0.768$ \\
\hline \multicolumn{5}{|c|}{ The risk score of fetal defects and pregnancy complications } \\
\hline Low-risk group, $\mathrm{n}(\%)$ & $552(37.9)$ & $245(44.4)$ & $307(55.6)$ & $\mathrm{p}^{\mathrm{chi2}}=0.149$ \\
\hline Intermediate-risk group, $\mathrm{n}(\%)$ & $873(60.0)$ & $418(47.9)$ & $455(52.1)$ & $\mathrm{p}^{\mathrm{chi2}}=0.762$ \\
\hline High-risk group, n (\%) & $30(2.1)$ & $18(60.0)$ & $12(40.0)$ & $\mathrm{p}^{\text {chi2 }}=0.267$ \\
\hline
\end{tabular}

$\mathrm{p}^{\text {chi2 }}$ - the $\mathrm{p}$-value from the chi-square test

\begin{tabular}{|c|c|c|c|}
\hline & OR & $95 \% \mathrm{Cl}$ & p \\
\hline \multicolumn{4}{|l|}{ Maternal age, years } \\
\hline $17-24$ & 1 (ref) & & \\
\hline $25-29$ & 2.31 & $1.18-4.53$ & $p=0.014$ \\
\hline 30-34 & 2.87 & $1.47-5.58$ & $p=0.002$ \\
\hline 35-39 & 1.79 & $0.95-3.37$ & $p=0.072$ \\
\hline$\geq 40$ & 1.34 & $0.66-2.75$ & $p=0.411$ \\
\hline \multicolumn{4}{|l|}{ Parity } \\
\hline First & 1 (ref) & & \\
\hline Second & 0.83 & $0.62-1.11$ & $p=0.212$ \\
\hline Third & 0.37 & $0.26-0.53$ & $\mathrm{p}<0.001$ \\
\hline$\geq$ Fourth & 0.23 & $0.15-0.37$ & $\mathrm{p}<0.001$ \\
\hline History of miscarriage (at least one) & 2.2 & $1.70-2.83$ & $\mathrm{p}<0.001$ \\
\hline \multicolumn{4}{|l|}{ Smoking status } \\
\hline Never smoked & 1 (ref) & & \\
\hline Smoked only before pregnancy & 0.53 & $0.41-0.71$ & $p<0.001$ \\
\hline Smoked before pregnancy and during first trimester & 0.18 & $0.08-0.43$ & $\mathrm{p}<0.001$ \\
\hline Hypothyroidism & 1.80 & $1.34-2.42$ & $\mathrm{p}<0.001$ \\
\hline Assisted reproductive technology & 2.25 & $1.18-4.31$ & $p=0.014$ \\
\hline
\end{tabular}

Multivariable logistic regression. All variables presented in a table were put into one model. $\mathrm{Cl}$ - confidence interval; OR — odds ratio

Similar results were obtained in a study by Medawar et al. [23], among Lebanese women where FA supplementation was used by $48 \%$ of women before pregnancy. Other studies undertaken in developed countries where women seem to pay more attention to pregnancy planning, have shown that less than half take FA supplements before pregnancy [24-28]. What is concerning is that only one in every two women with a history of any fetal defects, including NTDs, 
Table 4. Fetal anomalies detected during the first trimester in a cohort of 1,455 pregnant women according to folic acid supplementation declared before pregnancy and without supplementation before pregnancy

\begin{tabular}{|c|c|c|c|}
\hline & $\begin{array}{l}\text { Folic acid supplementation declared } \\
\text { before pregnancy } \\
\qquad n=681\end{array}$ & $\begin{array}{l}\text { Without folic acid supplementation } \\
\text { declared before pregnancy } \\
\qquad n=774\end{array}$ & p-value \\
\hline NTDs in a previuos pregnancy, $\mathrm{n}(\%)$ & $8(1.2)$ & $9(1.1)$ & $\mathrm{p}^{\text {chi2 }}=0.950$ \\
\hline NT $>95^{\text {th }}$ centile, $n(\%)$ & $46(6.7)$ & $52(6.7)$ & $\mathrm{p}^{\mathrm{chi2}}=0.891$ \\
\hline Chromosomal anomaly, $\mathrm{n}(\%)$ & $10(1.4)$ & $20(2.5)$ & $\mathrm{p}^{\mathrm{chi2}}=0.135$ \\
\hline NTDs, n (\%) & $1(0.1)$ & $6(0.7)$ & $\mathrm{p}^{\text {chi2 }}=0.417$ \\
\hline Omphalocele, $\mathrm{n}(\%)$ & $2(0.2)$ & $3(0.3)$ & $\mathrm{p}^{\mathrm{chi2}}=0.760$ \\
\hline Heart defects, $n(\%)$ & $8(1.2)$ & $6(0.7)$ & $\mathrm{p}^{\mathrm{chi2}}=0.436$ \\
\hline Other defects, $\mathrm{n}(\%)$ & $3(0.4)$ & $5(0.6)$ & $\mathrm{p}^{\mathrm{chi2}}=0.597$ \\
\hline Total, n (\%) & $24(3.5)$ & $40(5.1)$ & $\mathrm{p}^{\text {chi2 }}=0.759$ \\
\hline
\end{tabular}

NT - nuchal translucency; NTDs - neural tube defects; $p^{\text {chi2 }}$ - the $p$-value from the chi-square test

used FA supplementation. Studies conducted over the past fourty years found that supplementation with FA significantly reduces the risk of neural tube defects by $32-72 \%[5-9$, $21,28,29]$. In our study the prevalence of NTDs was $86 \%$ lower in the group of women who used FA supplementation compared with those who did not. Other recent studies also indicate the effect of supplementation on reducing the incidence of heart defects, urinary tract defects, limb defects, cleft lip and palate, and preeclampsia [9-17]. In our cohort we also noted a $62.5 \%$ lower prevalence of fetal defects other than NTDs in women who used FA supplementation.

Food fortification with FA may be the solution to the problem of inadequate FA supplementation. The United States of America (USA) was the first country to implement a national folic acid food fortification program in 1998 to prevent NTDs, and nowadays over 80 countries, but not Poland, fortify food with folic acid [21]. However, questions remain about the impact of food fortification in reducing the occurence of NTDs [21]. Some authors indicate that there is a very weak correlation between the incidence of NTDs and FA fortification levels, and that a woman's socioeconomic status may be more influential [21]. Our study did not analyze socioeconomic factors as these were the subject of previous studies $[17,30]$. On the other hand, some fetal defects may be related to chromosomal anomalies and other factors not related to FA deficiency.

Our study has some limitations. First, it was a retrospective study conducted in a single national referral centre. The incidence and levels of folic acid supplementation were declarative, and we did not measure actual FA intake against declared intake. The best way to check folate status is by measuring maternal red blood cell folate concentrations, because as it was published $\geq 906 \mathrm{nmol} / \mathrm{L}(400 \mathrm{ng} / \mathrm{mL})$ is associated with a significantly low risk of NTDs [31]. We believe that the obtained results indicate the need to organize a prospective study in which the reliability and validity of the applied survey will be determined.

\section{CONCLUSIONS}

Despite these limitations our study highlights the need for better health education among women of child-bearing age, during the periconceptional period, especially among those women with risk factors of folate deficiency and/or NTDs. As our research and data from the literature have shown, FA supplementation levels are still insufficient, even in developed countries. Our study provides solid basis for well planned larger cohort study wich would enable investigation of dietary and supplementary sources of FA, with folate blood concentration analyses giving the opportunity to analyse associated fetal risks.

\section{Conflict of interest}

All authors declare no conflict of interest.

\section{REFERENCES}

1. Oliver EM, Grimshaw KEC, Schoemaker AA, et al. Dietary habits and supplement use in relation to national pregnancy recommendations: data from the EuroPrevall birth cohort. Matern Child Health J. 2014; 18(10): 2408-2425, doi: 10.1007/s10995-014-1480-5, indexed in Pubmed: 24752313.

2. Brown B, Wright C. Safety and efficacy of supplements in pregnancy. Nutr Rev. 2020; 78(10): 813-826, doi: 10.1093/nutrit/nuz101, indexed in Pubmed: 31925443.

3. World Health Organization (WHO). WHO Recommendations on Antenatal Care for a Positive Pregnancy Experience. https://www.who. int/publications/i/item/9789241549912 (20 December 2020).

4. World Health Organization (WHO). WHO Antenatal Care Recommendations for a Positive Pregnancy Experience Nutritional Interventions Update: Multiple Micronutrient Supplements during Pregnancy. https:// www.who.int/ publications/i/item/9789240007789 (20 January 2021).

5. De-Regil LM, Peña-Rosas JP, Fernández-Gaxiola AC, et al. Effects and safety of periconceptional oral folate supplementation for preventing birth defects. Cochrane Database Syst Rev. 2015(12): CD007950, doi: 10.1002/14651858.CD007950.pub3, indexed in Pubmed: 26662928.

6. Prevention of neural tube defects: results of the Medical Research Council Vitamin Study. MRC Vitamin Study Research Group. Lancet. 1991; 338(8760): 131-137, indexed in Pubmed: 1677062. 
7. Czeizel AE, Dudás I, Vereczkey A, et al. Folate deficiency and folic acid supplementation: the prevention of neural-tube defects and congenital heart defects. Nutrients. 2013; 5(11): 4760-4775, doi: 10.3390/nu5114760, indexed in Pubmed: 24284617.

8. Bibbins-Domingo K, Grossman DC, Curry SJ, et al. US Preventive Services Task Force. Folic acid supplementation for the prevention of neural tube defects: US Preventive Services Task Force Recommendation Statement. JAMA. 2017; 317(2): 183-189, doi: 10.1001/jama.2016.19438, indexed in Pubmed: 28097362.

9. Wilson RD, Wilson RD, Audibert F, et al. Genetics Committee, Special Contributors. Pre-conception folic acid and multivitamin supplementation for the primary and secondary prevention of neural tube defects and other folic acid-sensitive congenital anomalies. J Obstet Gynaecol Can. 2015; 37(6): 534-552, doi: 10.1016/s1701-2163(15)30230-9, indexed in Pubmed: 26334606.

10. Yazdy MM, Honein MA, Xing J. Reduction in orofacial clefts following folic acid fortification of the U.S. grain supply. Birth Defects Res A Clin Mol Teratol. 2007; 79(1): 16-23, doi: 10.1002/bdra.20319, indexed in Pubmed: 17177274.

11. Liu C, Liu C, Wang Q, et al. Supplementation of folic acid in pregnancy and the risk of preeclampsia and gestational hypertension: a meta-analysis. Arch Gynecol Obstet. 2018; 298(4): 697-704, doi: 10.1007/s00404018-4823-4, indexed in Pubmed: 29978414.

12. https://www.who.int/elena/titles/folate_periconceptional/en/.

13. Cawley S, Mullaney L, McKeating A, et al. A review of European guidelines on periconceptional folic acid supplementation. Eur J Clin Nutr. 2016; 70(2): 143-154, doi: 10.1038/ejcn.2015.131, indexed in Pubmed: 26350391.

14. Bomba-Opoń D, Hirnle L, Kalinka J, et al. Folate supplementation during the preconception period, pregnancy and puerperium. Polish Society of Gynecologists and Obstetricians Guidelines. Ginekol Pol. 2017; 88(11): 633-636, doi: 10.5603/GP.a2017.0113, indexed in Pubmed: 29303218.

15. Zimmer M, Sieroszewski $\mathrm{P}$, Oszukowski $\mathrm{P}$, et al. Polish Society of Gynecologists and Obstetricians recommendations on supplementation during pregnancy. Ginekol Pol. 2020; 91(10): 644-653, doi: 10.5603/GP.2020.0159, indexed in Pubmed: 33184834.

16. Sedgh $G$, Singh $S$, Hussain R. Intended and unintended pregnancies worldwide in 2012 and recent trends. Stud Fam Plann. 2014; 45(3): 301-314, doi: 10.1111/j.1728-4465.2014.00393.x, indexed in Pubmed: 25207494.

17. Camier A, Kadawathagedara $M$, Lioret S, et al. Social inequalities in prenatal folic acid supplementation: results from the ELFE cohort. Nutrients. 2019; 11(5), doi: 10.3390/nu11051108, indexed in Pubmed: 31109064.

18. www.pacjent.gov.pl.

19. www.fetalmedicine.org.
20. Pietryga $M$, Borowski D, Brązert J, et al. Polskie Towarzystwo Ginekologiczne. [Polish Gynecological Society--Ultrasound Section Guidelines on ultrasound screening in uncomplicated pregnancy--2015]. Ginekol Pol. 2015; 86(7): 551-559, indexed in Pubmed: 26376536.

21. Kancherla V, Ibne Hasan MdO, Hamid R, et al. Prenatal folic acid use associated with decreased risk of myelomeningocele: A case-control study offers further support for folic acid fortification in Bangladesh. PLoS One. 2017; 12(11): e0188726, doi: 10.1371/journal.pone.0188726, indexed in Pubmed: 29190654.

22. Bitzer J, von Stenglin A, Bannemerschult R. Women's awareness and periconceptional use of folic acid: data from a large European survey. Int J Womens Health. 2013; 5: 201-213, doi: 10.2147/IJWH.S40149, indexed in Pubmed: 23658501.

23. Medawar G, Wehbe T, Jaoude EA. Awareness and use of folic acid among women of childbearing age. Ann Glob Health. 2019; 85(1), doi: 10.5334/aogh.2396, indexed in Pubmed: 30977622.

24. von Stenglin A, Buchwald S, Lynen R. Women's awareness and use of folate supplements prior to and during pregnancy: a global perspective. Eur J Contracept Reprod Health Care. 2010; 15(s1): 111-112.

25. Maher M, Keriakos R. Women's awareness of periconceptional use of folic acid before and after their antenatal visits. Clin Med Insights Womens Health. 2014; 7: 9-15, doi: 10.4137/CMWH.S13535, indexed in Pubmed: 24817820.

26. Luton $D$, Forestier $A$, Courau $S$, et al. Preconception care in France. Int J Gynaecol Obstet. 2014; 125(2): 144-145, doi: 10.1016/j.ijgo.2013.10.019, indexed in Pubmed: 24552853.

27. Agricola E, Gesualdo F, Pandolfi E, et al. Does googling for preconception care result in information consistent with international guidelines: a comparison of information found by Italian women of childbearing age and health professionals. BMC Med Inform Decis Mak. 2013; 13: 14, doi: 10.1186/1472-6947-13-14, indexed in Pubmed: 23347453.

28. Busby A, Abramsky L, Dolk H, et al. Eurocat Folic Acid Working Group. Preventing neural tube defects in Europe: population based study. BMJ. 2005; 330(7491): 574-575, doi: 10.1136/bmj.330.7491.574, indexed in Pubmed: 15760997.

29. Czeizel AE, Dudás I. Prevention of the first occurrence of neural-tube defects by periconceptional vitamin supplementation. N Engl J Med. 1992; 327(26): 1832-1835, doi: 10.1056/NEJM199212243272602, indexed in Pubmed: 1307234.

30. gis.gov. pl > wp-content > uploads > 2018/04 > Raport z badania „Zachowania zdrowotne kobiet w ciąży". Warszawa 2017.

31. Murphy ME, Westmark CJ. Folic acid fortification and neural tube defect risk: analysis of the food fortification initiative dataset. Nutrients. 2020; 12(1), doi: 10.3390/nu12010247, indexed in Pubmed: 31963665. 